ENSAYO

\title{
ADAM SMITH: FILÓSOFO DE LA RAZÓN PRÁCTICA*
}

\author{
María Alejandra Carrasco
}

\begin{abstract}
En este trabajo se propone que la Teoría de los Sentimientos Morales (TSM) de Adam Smith, aun cuando tradicionalmente se la interpreta como una ética sentimentalista, puede interpretarse también, razonablemente, como una ética fundada en la razón práctica. En efecto — se señala—, Smith rescata algunos conceptos fundamentales de la tradición moral aristotélica y los integra, en un todo coherente, con las nociones de universalidad e imparcialidad propias de la Ilustración. Esta visión global de la ética, que establece un mínimo moral y señala un máximo moral, transforma a la TSM en una de las más completas e interesantes teorías éticas modernas.
\end{abstract}

María Alejandra Carrasco. Doctora en Filosofía, Universidad de Navarra. Profesora del Instituto de Filosofía de la Pontificia Universidad Católica de Chile. Entre sus publicaciones están los libros Consecuencialismo. Por Qué No (Eunsa, 1999) y Ética y Liberalismo: Reflexiones Políticas a la Luz de la Filosofía de Charles Taylor (Ril Editores, 2001) y numerosos artículos en revistas especializadas.

* La realización de este artículo ha sido posible gracias al financiamiento de Conicyt, proyecto Fondecyt \# 1060673. 


\section{E}

la séptima y última parte de la Teoría de los Sentimientos Morales ${ }^{1}$ Adam Smith clasifica su teoría, al igual que la de su maestro Francis Hutcheson y su gran amigo David Hume, entre aquellos sistemas que hacen de los sentimientos el principio último de aprobación moral² ${ }^{2}$ Básicamente esta escuela del sentimentalismo inglés, de la que Smith sin duda se siente parte, es una reacción tanto a las teorías éticas egoístas de Hobbes y Mandeville como a las teorías racionalistas de algunos de sus predecesores modernos (los platonistas de Cambridge, fundamentalmente ${ }^{3}$ ). En consecuencia, y dando por descartados los sistemas teológicos medievales y cualquier otra ética que implicara algún compromiso metafísico, los empiristas de la Ilustración Escocesa encontraron en los sentimientos la base natural para fundar la moralidad. Hutcheson y Hume lograron su objetivo. Pero Smith, particularmente debido a la introducción de su peculiar concepto de simpatía y del supuesto espectador imparcial en su teoría moral ${ }^{4}$, acabó estructurando un sistema que puede plausiblemente ser entendido como una ética de razón práctica5

${ }^{1}$ En adelante TSM. Smith publicó esta obra por primera vez en 1759 y la reeditó cinco veces antes de su muerte. En la sexta edición (1790) incorporó un capítulo enteramente nuevo y desarrolló algunos temas a los que sólo había hecho alusión en las versiones anteriores. A mi juicio, esta última edición contiene la evidencia más sólida para incluir a Smith en la tradición ética de la "razón práctica”, en contraste con la escuela sentimentalista de su época. Mis referencias al libro serán extraídas de esta última edición, preparada por David Daiches Raphael y Alec Lawrence Macfie (Indianapolis: Liberty Classics, 1976). La traducción de las citas es mía. Las referencias incluyen al final la página según la edición en castellano de Carlos Rodríguez Braun (Alianza, 1997). Para el detalle de las referencias de TSM, véase la sección a) de la bibliografía al final del artículo.

${ }^{2}$ Véase TSM VII.iii.3.

${ }^{3}$ Smith sólo nombra a Ralph Cudworth (1617-1688) en representación de esta escuela (TSM VII.iii.2.4, 557). Según esta ética, las ideas del bien y del mal están antes de toda ley y experiencia, y desde ellas se deduciría lo que es bueno o malo en cada situación particular. Smith, en cambio, sostiene que "Es completamente absurdo e ininteligible suponer que las percepciones primarias de lo bueno y lo malo procedan de la razón” (TSM VII.iii.2.5, 557), aunque sí reconoce el papel de la razón en la inducción de las reglas generales de moralidad.

${ }^{4}$ Para la originalidad de la descripción que Smith realiza del espectador imparcial, véase Fleischacker (1991), nota 18.

${ }^{5}$ Ésta es una interpretación algo heterodoxa dentro de los estudiosos de la teoría moral de Adam Smith, que en términos generales reafirman su pertenencia a la escuela del sentimentalismo. No obstante, en estos últimos años han surgido voces que destacan ciertos elementos que no podrían pertenecer a una ética propiamente sentimentalista (véase, por ejemplo, Berns, 1994; Fleischacker, 1999, 2004; Griswold, 1999, y Vivenza, 2001). Con todo, ninguno de ellos intenta una interpretación unificada de la teoría moral de Smith como una teoría de la razón práctica. 
¿Cómo no se dio cuenta de las grandes diferencias de su sistema frente a los sentimentalismos contemporáneos? Probablemente, como él mismo reconoce al identificar los "principios de aprobación” de los distintos sistemas morales, éste no era más que un "asunto de mera curiosidad filosófica”6 para él, que no ameritaba mayor atención dada su nula incidencia en la práctica. Afirmar que nuestras nociones del bien y del mal derivaban de los sentimientos ${ }^{7}$ bastó a Smith para considerarse un sentimentalista. Sin embargo, y aunque obviamente éste no fue nunca su proyecto, las profundas y perspicaces observaciones del comportamiento humano y de la gestación de la evaluación moral que realiza permiten re-construir, al menos parcialmente, el entramado teórico y la justificación racional última que subyace a su teoría. Mi propuesta es que, lejos de un sentimentalismo, la TSM es una ética que se acerca más a la razón práctica, y conforma uno de los sistemas morales más atractivos de la Era Moderna, capaz de conciliar, en una teoría única y consistente, elementos de la ética de la virtud clásica con otros rasgos propios de los sistemas modernos. En la primera sección de este ensayo mostraré por qué la ética de Smith no puede interpretarse como un sentimentalismo moral. En la segunda me centraré en una breve descripción de algunos elementos clave de la racionalidad práctica, tanto en su versión aristotélica como contemporánea. Y en la tercera sección, finalmente, intentaré aplicar estos conceptos a la TSM de Smith, para mostrar cómo su teoría podría plausiblemente interpretarse como una ética de la razón práctica, conciliando características que, en términos generales, se han visto como contradictorias y excluyentes.

\section{Sentimentalismo o racionalidad práctica}

Diversas causas históricas y culturales pueden haber influido para que la teoría de Smith no se interpretara como una ética de la razón práctica. Durante la Modernidad este concepto había caído en desuso, y permaneció así hasta que Kant lo rehabilitara, aunque de una manera muy distinta a la tradicional, a fines del siglo XVIII ${ }^{8}$. De hecho Smith, en toda la obra, utiliza

\footnotetext{
${ }^{6}$ TSM VII.iii.introd.3, 550.

${ }^{7}$ Véase TSM I.iii.3. Por ejemplo, en I.i.3.1, 62: "En toda ocasión serán sus propios sentimientos la norma y medida para juzgar los míos”.

${ }^{8}$ Fuera de estudios específicos sobre Aristóteles, sólo alrededor de 1960 el concepto clásico de racionalidad práctica fue reconsiderado en el debate filosófico, principalmente a través del movimiento intelectual alemán que en la actualidad se ha hecho conocido con el nombre de "la rehabilitación de la razón práctica". Esta antigua tradición se conoce hoy también como el "giro narrativo" que distingue a la razón práctica del intento moderno de dar cuenta de ella desde la razón teórica, la que omite necesariamente aspectos esenciales de la constitución de la praxis.
} 
58 veces la palabra "razón”, en el sentido de la facultad de la razón. En 28 oportunidades se refiere evidentemente a la razón teórica ("razón y filosofía”, “no recomendado a la razón”, "la fría razón”, etc.) y en 4, a la razón técnica. Sólo en una ocasión alude explícitamente a la razón práctica: cuando expone la ética de Aristóteles en VII.2.212, 484-486. Gran parte de su crítica a los estoicos ${ }^{9}$ y de su breve crítica a Platón ${ }^{10}$ estriba precisamente en el excesivo racionalismo que ellos exhiben (el cual se refleja en su desdén por las pasiones y en el punto de vista universal de sus juicios morales). Asimismo, cuando rechaza la moralidad basada en la utilidad, también se está oponiendo a la razón como principio de aprobación moral: la única facultad mediante la cual seríamos capaces de "ver [las cosas] bajo esa luz abstracta y filosófica"11 que es necesaria para calcular las consecuencias ${ }^{12}$. En esto Smith es categórico: "Cuando consideramos la virtud y el vicio de un modo general y abstracto, las cualidades que provocan estos diversos sentimientos parece como si, en buena parte, desaparecieran”"13.

Ahora bien, si ni el amor a sí mismo ${ }^{14}$ ni la razón teórica pueden fundar la moralidad, y si el concepto de razón práctica no está presente en su tradición, la única posibilidad que queda son los sentimientos ${ }^{15}$. "Estas percepciones primarias [del bien y del mal] [...] no pueden ser objeto de la razón sino de un sentido inmediato y de los sentimientos. Si bien es cierto que las reglas morales generales se forman tras descubrir en una amplia variedad de casos que un modo particular de conducta nos agrada, y que al mismo tiempo otro modo de conducta nos desagrada constantemente, la razón no puede hacer que un objeto resulte agradable o desagradable por sí mismo [...] Nada puede ser agradable o desagradable por sí mismo, más que cuando así lo ha sido presentado por la sensación y el sentimiento inmediatos”16. En otras palabras, Smith afirmaría que como nuestras primeras nociones del bien y del mal provienen de las percepciones de lo agradable y lo desagradable, los sentimientos serían el principio de acuerdo con el que aprobamos o desaprobamos la conducta de los demás: sentimentalismo.

${ }^{9}$ Véase, por ejemplo, TSM VII.ii.1.35 a 43, 486-514.

${ }^{10}$ Véase TSM VII.ii.1.14, 480.

${ }^{11}$ TSM IV.1.9, 331.

${ }^{12}$ Véase su crítica a las teorías (proto) utilitaristas en la cuarta parte de la TSM.

13 TSM 4.2.2, 338.

${ }^{14}$ Véase TSM VII.3.1. Hobbes y Mandeville son los más conocidos representantes de esta corriente.

${ }^{15}$ Smith no razona mediante el método de descarte aquí descrito, sino tal vez en la séptima parte de la TSM. La verdadera explicación de su sistema, expuesta en las seis partes anteriores, se basa mucho más en la observación empírica que en esta clase de razonamientos.

${ }^{16}$ TSM VII.iii.2.7, 558. 
Pero hay un punto clave que permitiría cuestionar la misma interpretación que Smith hace de su obra, cual es la importancia central que él mismo da a la virtud del autodominio (self-command) ${ }^{17}$. Al hablar de ésta dice que desde la niñez se nos debe enseñar "a moderar nuestras pasiones" y "a ejercer una disciplina sobre nuestros propios sentimientos"18 — hábitos que debemos cultivar a lo largo de toda nuestra vida. Asimismo, señala que "el hombre justo y sabio [...] mantiene en toda ocasión este control sobre sus sentimientos pasivos”19. Y agrega luego que ni el hombre más sabio y decidido puede identificarse perfectamente con el espectador ideal porque "en los paroxismos de la aflicción [...] sus sentimientos naturales le urgen" ${ }^{20}$. Además, cuando describe los sistemas morales en los que la virtud consiste en actuar con propiedad (como su propia teoría), dice que el carácter virtuoso reside precisamente en "el adecuado gobierno y dirección de todos nuestros afectos" ${ }^{21}$. ¿Qué significa esto? Parece claro que Smith no cree que nuestras nociones del bien y mal moral deriven de nuestros sentimientos brutos o naturales, de nuestra psicología innata, sino más bien de nuestros sentimientos ya informados por el espectador imparcial. Antes del desarrollo de este "hombre dentro del pecho", simplemente no formulamos juicios morales ${ }^{22}$. Y desde que se desarrolla y comienza a vivir en nuestro interior, nuestros juicios morales dependen más de "sus" sentimientos que de nuestros propios sentimientos naturales subjetivos e inestables $^{23}$. La moralidad, en este sentido, sería como una estructura de segundo orden que se monta sobre nuestra psicología, sobre nuestras tendencias innatas. Esta estructura, que se manifiesta en el sentido de propie-

${ }^{17}$ Muchos estudiosos de Smith, como por ejemplo Montes (2003), afirman que el autodominio es una "meta-virtud”, una virtud necesaria para tener cualquier otra virtud.

${ }^{18}$ Véase, en general, TSM III.1.

${ }^{19}$ TSM III.iii.22, 273.

${ }^{20}$ TSM III.iii.28, 274. Cursivas mías.

${ }^{21}$ TSM VII.ii.introd.2, 477.

22 Véase TSM III.1. Griswold (1999: 46) contrasta los sentimientos "morales" con los sentimientos intelectuales (asombro, sorpresa y admiración). Sin rechazar esa distinción, estimo que también es correcto, y particularmente útil, comparar los sentimientos "morales" con los sentimientos no morales o pre-morales. De hecho, incluso sería posible establecer una analogía entre este contraste y el de la voluntad y la buena voluntad de Kant, donde la última está informada y justificada por la razón, y, en consecuencia, es propiamente "moral". Por otra parte, al fundar la conducta moral en los sentimientos (aunque sentimientos informados por el espectador imparcial), Smith sugiere acertadamente que el mero reconocimiento intelectual del bien no es suficiente para la praxis ética.

${ }^{23}$ El ejemplo más claro lo da Smith en TSM I.i.3.4, 64, al explicar la "simpatía condicional”. 
dad o los juicios del espectador imparcial, va surgiendo poco a poco en nuestro proceso de socialización; no nacemos con ella, pero necesariamente la adquirimos en cuanto tenemos la tendencia innata de la simpatía (queremos ser aceptados por los demás) y nos damos cuenta de que sin "dominar" nuestros sentimientos subjetivos o "naturales, de primer orden" — con los que nacemos y sentimos que somos el centro del universo- no alcanzaremos nunca la simpatía de otros.

De aquí que en la TSM la percepción de lo moralmente bueno no corresponde exactamente a la percepción de lo "agradable" sino a la percepción de lo "apropiado" (que, en cuanto se simpatiza, suele también ser agradable). Si el principio de aprobación moral derivara sólo de los sentimientos brutos o naturales, no se requeriría de la virtud del autodominio, ni de la experiencia ni del espectador imparcial para formular juicios éticos. El mecanismo de nuestra naturaleza que nos permite identificar el bien y el mal, en la teoría de Smith, ciertamente incluye los sentimientos, pero son sentimientos ya informados por el espectador imparcial ("sentimientos de segundo orden”). Así, cuando Smith declara que "en toda ocasión serán sus propios sentimientos [los del agente] la norma y medida para juzgar los míos”24, debe estar afirmando que en el juicio moral los sentimientos que intervienen son los del espectador imparcial, esto es, los sentimientos apropiados o ya informados por la razón, los sentimientos morales. Asimismo, cuando dice que "nada puede ser agradable o desagradable por sí mismo, sino cuando así nos lo ha sido presentado por la sensación o el sentimiento inmediatos" ${ }^{25}$, se refiere, como afirma Charles Griswold, a una percepción moral que trasciende la simple intuición, e incluye una mezcla de deliberación, comprensión y penetración intuitiva ${ }^{26}$.

Ello resulta particularmente importante para mi tesis, puesto que la percepción — como ya veremos— forma parte constitutiva de la razón práctica y puede manifestarse por medio de las emociones, como sucede en el sistema de Smith donde "la percepción moral es obra del sentimiento de simpatía”27. De hecho, se puede sostener que el ejercicio de la virtud aristo-

${ }^{24}$ TSM I.i.3.1. Cfr. nota 7; TSM I.i.3.1, 62.

${ }^{25}$ TSM VII.iii.2.7, 558.

${ }^{26}$ Griswold (1999: 88). (En inglés: deliberation, understanding and insight.)

${ }^{27}$ Griswold (1998: 30). Con todo, Griswold no cree que Smith y Aristóteles coincidan en este punto. Mi impresión, en cambio, es que la percepción moral para Aristóteles, al igual que para Adam Smith, supone por lo menos un ejercicio habitual de reflexión e interpretación. Si así no fuera, la educación moral sería inútil y Aristóteles no se hubiera dado el trabajo de recalcar tanto la importancia de la experiencia cuando se trata de dotar de contenido a la sabiduría práctica, distinguiendo con ello el conocimiento práctico del conocimiento científico y matemático. Véase Aristóteles, Nicho- 
télica de la prudencia es la percepción moral, es el "ojo de la razón”, que captura inmediatamente la virtud ${ }^{28}$. Del mismo modo, cuando Smith habla del testimonio del supuesto espectador imparcial, aclara que éste corrige los defectos del "ojo natural de la mente", la parcialidad de los sentimientos brutos $^{29}$, a fin de juzgar con propiedad. En otras palabras, Smith está diciendo que el supuesto espectador imparcial es como un "ojo adquirido de la mente”, algo que parece ser muy similar a la virtud aristotélica de la pruden$\mathrm{cia}^{30}$.

\section{Razón práctica}

La razón práctica no es una facultad distinta de la razón, sino la misma razón guiando la acción humana. Pero cuando la razón opera de este modo, su objeto (la acción) es tan distinto al de la razón teórica (conocimiento universal), que no sólo difiere de esta última en su contenido sino también en su estructura. Aristóteles, en la Antigüedad, fue quien mejor describió el funcionamiento de la razón en el ámbito práctico. Los racionalismos modernos posteriores, sin embargo, oscurecieron y desvirtuaron la llamada filosofía práctica hasta que en la segunda mitad del siglo XX ha habido una cierta recuperación de ésta, y una rearticulación particularmente fructífera para entender la filosofía moral de Adam Smith.

maquean Ethics [Ética a Nicómaco] (en lo sucesivo EN) 6.8, 1142a12-21, en The Complete Works of Aristotle [“Obras completas de Aristóteles”], Jonathan Barnes, ed. (1984).

Por otra parte, Nussbaum (1999) hace hincapié en el papel de las emociones en la percepción moral aristotélica. Señala: “A mi juicio [...] la percepción no está meramente asistida por la emoción sino que también está en parte constituida por una respuesta apropiada [...] Y no es sólo que a veces necesitemos las emociones para llegar $a$ una percepción correcta (intelectual) de la situación: eso es verdad, pero no es la historia completa [...] Las emociones son en sí mismas modos de percibir o de reconocer. Sus respuestas son parte de aquello en lo que consiste conocer, vale decir, aquello en lo que consiste reconocer o admitir verdaderamente" (170-171).

${ }^{28}$ Véase Aristóteles, EN 6.12, 1144a29. Una vez más, esta "percepción inmediata” entraña reflexión, y sólo puede ser “inmediata” porque es una virtud, un hábito adquirido.

${ }^{29}$ Véase TSM III.3.2, 237.

30 Tanto Vivenza (2001: 48) como Griswold (1999: 190) plantean una cierta analogía entre el phronimos (hombre de sabiduría práctica) aristotélico y el espectador imparcial; admitiendo que el concepto de Smith es mucho más complejo y elaborado, y, por tanto, diferente. Mi impresión es que la analogía no debe hacerse con el phronimos sino con la virtud de la prudencia (hábito adquirido a través del ejercicio y que dispone para escoger el bien en toda ocasión). No obstante, concuerdo plenamente con ellos en que esta analogía es más bien laxa y no puede ser llevada a una identidad. 


\subsection{Aristóteles}

Hay tres elementos propios de la tradición aristotélica de la razón práctica que quisiera destacar en este ensayo, por su diferencia radical con las corrientes racionalistas y sentimentalistas y su coincidencia con la teoría moral de Smith.

En primer lugar, la teleología. La justificación de la ética aristotélica es teleológica, vale decir, una acción es éticamente correcta en la medida en que se adecue y realice lo que para Aristóteles es el fin de la vida humana: la eudamonia. En la TSM la justificación moral no parece ser teleológica (de hecho se podría sintetizar en la aprobación del espectador imparcial) ${ }^{31}$, pero la teoría de la acción de Smith, o el operar de la razón práctica, sí coincide con la descripción que hace Aristóteles de ésta. Y éste es el punto decisivo: en Aristóteles, la misma estructura y operación de la razón práctica es teleológica $^{32}$. Los agentes racionales humanos ordenan su vida (sus acciones) con respecto a ciertos fines. Todos estamos abiertos (o "lanzados") hacia el futuro, vivimos con un ojo puesto en el presente y el otro en el futuro, y ése es el horizonte que ilumina y da sentido a nuestras acciones actuales. La prueba de esta “doble mirada” propia de los agentes racionales es clara en los conflictos de motivación o de deseos. Todos hemos tenido la experiencia de sentir algún intenso deseo sensible ("quiero un helado”) que se contradice con alguna otra motivación o algún otro deseo más profundo (“quiero ser una top model profesional”). Aristóteles atribuye este conflicto a los caracteres continentes e incontinentes ${ }^{33}$, y a través de su descripción muestra que, al margen de nuestros deseos inmediatos, todos tenemos también algunos fines o motivaciones mediatos, futuros y más estables. Concretamente, todos tenemos alguna representación, más o menos precisa, de qué es para nosotros una vida feliz (una vida plena) ${ }^{34}$. Este fin último personal, que nos permite integrar nuestros infinitos fines parciales, vendrá a ser

${ }^{31}$ Véase mi “Adam Smith: Liberalismo y Razón Práctica” (2006: 43-69). Allí argumento que la justificación de sus juicios morales es incluso deontológica, aunque también, como aludiré más adelante y desarrollé en mi “Adam Smith: Modern Reconstruction of Practical Reason” (2004), para los hombres de virtud perfecta la justificación moral de sus acciones sí podría interpretarse como teleológica.

32 Este concepto suele ser malinterpretado por los comentaristas modernos como si significara determinismo o providencialismo. Yo, en cambio, sigo aquí la concepción que me parece más correcta: Véase Vigo (1996: capítulo 3). Véase también Cooper (1975: 15-18 y 93-97). Aun cuando Cooper no utiliza la palabra "teleología" para referirse a esta característica, reconoce que la idea aristotélica de razón práctica presupone la orientación a un fin.

${ }^{33}$ Véase Urmson (1973: 223).

${ }^{34}$ Véase Irwin (1980: 46-47). 
la justificación última de nuestras acciones particulares ${ }^{35}$. Es decir, y aunque Aristóteles no utiliza estas palabras, para él la teleología es la posesión de una comprensión global de nuestra propia vida con respecto a cierta representación ideal de la vida buena o feliz ${ }^{36}$.

Asimismo, el conflicto de motivación o de deseos en la ética de Aristóteles supone otra cosa importante, a saber: que los seres humanos usamos la razón para guiar nuestras acciones. Como sólo la mediación racional nos permite distanciarnos del contexto inmediato de la acción para verlo en relación con la totalidad de nuestra vida, el conflicto muestra que somos capaces, en tanto seres racionales, de dirigir nuestras acciones hacia ese ideal razonable, siguiendo nuestros deseos más profundos (que no son necesariamente los inmediatos) ${ }^{37}$. ¿Cómo lo hacemos? A través de la proiaresis o decisión deliberada. $\mathrm{Y}$ en este sentido la teleología y la deliberación racional están intrínsecamente conectadas: vivir de acuerdo con la proiaresis es dotar a nuestra vida de un fin, de un telos.

${ }^{35}$ Ello se puede afirmar aun cuando no haya una deliberación real. Acerca de este tema Cooper (1975) señala que: "En la medida en que ésas sean nuestras razones últimas, es como si hubiéramos deliberado y decidido en conformidad con ellas (aun cuando no hayamos realizado ninguna deliberación actual)” (9-10).

${ }^{36}$ Aristóteles, como se sabe, también postula un contenido objetivo para esta vida buena o eudaimonia, que no viene definido por los deseos subjetivos del agente sino por un bien real para los seres racionales humanos. Este fin consistiría en el ejercicio de la virtud; en primer lugar de la contemplación (virtudes intelectuales), y en segundo lugar de la vida política (virtudes morales). No obstante, y en contraste con Platón y con el estoicismo, Aristóteles afirma que esta eudaimonia tiene también alguna relación con la fortuna externa (véase EN 1.8, 1099a32-b7). De modo que no dice que el hombre virtuoso será necesariamente feliz; pero sí que no puede ser infeliz (véase EN 1.10 1101a6-7). A través de las complejas relaciones entre felicidad, virtud y fortuna externa, la concepción aristotélica de felicidad se sitúa, por medio de un delicado equilibrio, en una posición intermedia entre dos extremos opuestos: la felicidad como bienestar material y el intelectualismo socrático y estoico (véase Vigo, 1996, capítulo 3). En Adam Smith, por su parte, el sabio y virtuoso, a diferencia de los estoicos y Platón, también requiere algo de fortuna externa y puede no ser feliz, aunque nunca infeliz (véase TSM III.1).

Todo lo dicho en esta nota, sin embargo, implica que Aristóteles cimienta su ética en la teleología propia de la operación de la razón práctica. No obstante, la estructura de la razón práctica ofrece también otras posibilidades para fundamentar y justificar la moralidad, por lo que no debe equipararse una ética de la razón práctica con una ética teleológica. Un buen ejemplo es el de tener como fin el de "mejorar nuestra propia condición”, por medio de fines más inmediatos como los de obtener la simpatía.

${ }^{37}$ Véase Burnyeat (1980), donde describe al hombre acrático como aquel que experimenta un deseo razonado de hacer una cosa, aunque, bajo la influencia de un deseo contrario, en la práctica hace otra. La persona prudente, en cambio, realiza el deseo razonado aun en contra del deseo inmediato (no se come el helado para no engordar y poder ser una top model). 
Fuera de la teleología, una segunda característica de la ética de Aristóteles es la relación que existe entre la razón práctica y las emociones. Aristóteles, a diferencia de los estoicos y de Kant, incorpora las emociones en la acción moral ${ }^{38}$. Para él las emociones son pre-cognitivas, y se desarrollan y perfeccionan mediante la cognición; son fundamentales en nuestra relación con el mundo de los valores y cumplen un doble papel en la ética: una función limitativa y una orientación positiva. Con todo, las emociones no son el fundamento de los valores, pues la acción moral, tanto la evaluación como la realización propiamente, requiere la ayuda de la razón ${ }^{39}$. Dejadas a sí mismas, lo que equivaldría a lo que anteriormente llamé "sentimientos brutos o naturales”, las emociones no son una guía adecuada para la acción. En la filosofía aristotélica, por tanto, la acción moral sí encarna emociones; pero emociones, por así decirlo, de "segundo orden”.

Finalmente, la conexión entre la teleología (como una vida guiada e integrada por su fin) y las emociones, se realiza en la llamada virtud. La virtud para Aristóteles es el hábito adquirido de elegir el medio con relación a nosotros, determinado por la razón y tal como lo elegiría un hombre prudente $^{40}$. Es un hábito adquirido y debe ser educado ${ }^{41}$. Y como las virtudes morales o virtudes de la razón práctica también se relacionan con las emociones, estas virtudes no se adquieren por demostración lógica ni por el mero estudio. La educación moral es la educación de las emociones de acuerdo con la razón, y se realiza a partir de los sentimientos naturales de placer y dolor que se van gradualmente reorientando hacia "objetos buenos” ${ }^{2}$. Adquirir la virtud moral requiere experiencia y ejercicio, de modo que el agente racional va incorporando, mediante la habituación, ciertos patrones de decisión racional que le permiten actuar con facilidad y rapi$\operatorname{dez}^{43}$.

${ }^{38}$ Para este tema véase especialmente Baillie (1988: 221), y Sherman (1999), p. 238, quien describe las emociones en Aristóteles como intencionales y cognitivas.

${ }^{39}$ Sherman (1999: 235), observa: "La parte desiderativa del alma no racional (apetitos, emociones y sentimientos) no se dedica a razonar, pero puede atender a la razón, puede ser moldeada por ella”.

${ }^{40}$ Véase EN 2.6, 1106b36-1107a3.

${ }^{41}$ Véase Burnyeat (1980: 111).

42 Véase Sherman (1999: 238).

${ }^{43} \mathrm{Al}$ plantear este argumento quisiera subrayar las similitudes en la comprensión de la educación moral que se pueden encontrar entre Aristóteles y Adam Smith, independientemente de las diferencias formales en cuanto a su estilo y a nivel de análisis. Véase especialmente TSM III.3.14.21-22, 259-260, 262; también TSM VI.iii.25, 442; y para Aristóteles, Sherman (1999: 257). Volveré sobre este punto en la sección 3. 
Estas tres características concretas (estructura teleológica de la acción, rol de las emociones en la ética y adquisición de virtudes) se enmarcan, en el pensamiento moral de Aristóteles, dentro de una perspectiva comprensiva, realista y de sentido común, que parte desde la observación empírica y cuyo imperativo implícito pareciera ser la moderación. En la tercera sección procuraré mostrar que muchas de estas características específicas e intuiciones generales están también presentes en la TSM. De hecho, no es casual que Smith, tal como Aristóteles en la Ética a Nicómaco ${ }^{44}$, concluya su obra tendiendo un puente hacia su teoría política, enfatizando así en la continuidad de estas dos esferas. ¿Por qué esta semejanza? Pues porque para Smith, al igual que para Aristóteles, el principio común de la jurisprudencia y de la ética se relaciona precisamente con la posibilidad de otorgar un orden racional a la contingencia: la razón práctica.

\subsection{Corrientes contemporáneas}

Tal como afirmé en el comienzo de esta sección, en las últimas décadas se ha retomado y estudiado de un modo más analítico la antigua tradición de la razón práctica. Entre los filósofos que han enfatizado este punto se encuentran, por ejemplo, Wolfgang Wieland y Thomas Nagel. Estos dos pensadores provienen de tradiciones muy distintas, pero ello, más que obstaculizar su estudio, sirve de complemento para entender mejor el concepto de racionalidad práctica. Wieland ${ }^{45}$ resalta su estructura básica: a diferencia de la razón teórica, que sólo trata con lo universal, la razón práctica tiene también que tratar con los particulares, con la contingencia, por cuanto su propósito es, precisamente, guiar la acción humana que estará siempre inserta en el mundo real contingente. Esta "heterogeneidad categorial", como él la denomina, fija ciertos límites estrictos a la razón, pues la relación que se da entre la universalidad de las normas y la particularidad de las acciones —o "el instalarse de la razón en nuestras preferencias y aversiones”, según las palabras de Robert Sokolowski ${ }^{46}$ — no es en absoluto sencilla. La reali-

${ }^{44}$ Aristóteles también señala: "La prudencia política y la práctica equivalen al mismo estado de ánimo, pero no es lo mismo ser un hombre de prudencia política que uno de prudencia práctica”, EN 1141b24-25. Cooper lo explica así: "El punto de Aristóteles es que la sabiduría política y el intelecto práctico corresponden efectivamente a la misma aptitud aunque, pero aplicada a contextos diferentes” (1975: 34-35).

${ }^{45}$ Véase Wieland (1989: 65; 1974: 17-42). La traducción de éste y otros textos de Wieland se encuentran en Alejandro Vigo (1996).

${ }^{46}$ Sokolowski (1989: 26). 
dad empírica sobrepasará siempre, excederá, contendrá más elementos que las normas universales, puesto que además de la infinidad de circunstancias particulares que las normas no pueden prever, existen también elementos situacionales que son por definición irreductibles a una teoría universal (como la irrepetibilidad: nunca una situación puede ser igual a otra, pues al menos el tiempo ha cambiado). Esta diferencia fundamental entre la teoría y la praxis es la misma que expresa Aristóteles al señalar que el ideal matemático es completamente inadecuado para la moral, queriendo decir que no podemos esperar la misma precisión en todos los temas, sino que de cada cual lo que su objeto permite ${ }^{47}$. En pocas palabras, las normas universales de la razón resultan insuficientes para guiarnos en circunstancias prácticas, ya que siempre quedará cierto residuo no capturado por la universalidad, que impedirá subsumir exhaustivamente las materias prácticas contingentes en una serie de principios generales ${ }^{48}$.

Ahora bien, esta heterogeneidad de niveles impone límites a la razón teórica, por lo que no le basta aplicar sus esquemas universales a las acciones particulares. Como las circunstancias de la realidad son infinitas y contingentes, la razón teórica ignora cuál de sus esquemas escoger o qué aspecto de la realidad debe poner entre paréntesis en cada ocasión particular. Tampoco pueden existir reglas universales para realizar esta operación, ya que cada situación es siempre absolutamente nueva, y en cada problema hay que volver a encontrar la mejor solución. En este sentido, la universalidad de la razón no es suficiente para la práctica. Se requiere de otra facultad para completar el proceso: la facultad del juicio (o la virtud aristotélica de la prudencia). Dicha facultad — señala Wieland— es capaz de conectar estos dos niveles (universalidad de la razón y particularidad del mundo real) en cada acción específica. Lo hace de modo habitual, de acuerdo con las normas culturales internalizadas y con nuestro propio aprendizaje moral, y no solemos ser conscientes de ello salvo en situaciones de conflicto. Algo muy similar, como ya veremos, al espectador imparcial de Adam Smith.

Así, la razón práctica posee una estructura heterogénea, que incluye tanto a la universalidad de la razón como la apertura al contexto (a las circunstancias específicas de cada situación particular). También está cons-

${ }^{47}$ Véase EN 1094b13-14.

${ }^{48}$ Véase Hutchinson (1986: 4): “Así, Aristóteles tiene dos motivos para creer que la ética no es principalmente una cuestión de enumerar principios de conducta. Primero, que la mera adquisición de esos principios es ineficaz, excepto en circunstancias especiales, cuando ya poseemos las virtudes; y segundo, que esos principios son necesariamente insuficientes frente a la irregularidad y la individualidad de los asuntos prácticos, lo que significa que deben complementarse con cierto tipo de habilidad perceptiva, que sólo viene con las virtudes”. 
titutivamente ligada a la facultad de juicio, que funciona como el "ojo de la razón”, determinando en cada ocasión qué es lo que se debe hacer. En este sentido se puede decir que el razonamiento moral es una suerte de juicio sensible ${ }^{49}$, que integra la percepción y sensibilidad moral, junto con el contexto concreto en que se realiza y la relatividad del agente (pues si verdaderamente hablamos de situaciones reales, el agente no puede nunca ser eliminado). Dicho de otro modo, la razón práctica incluye el pathos y el ethos ${ }^{50}$; aunque, como es razón, también genera necesariamente un autodistanciamiento al introducirse en las pasiones ${ }^{51}$. Pareciera así que este "pensamiento o juicio sensible" es la única posibilidad que tiene la razón para tratar con aquellos contenidos que no pueden ser reducidos exhaustivamente a símbolos abstractos, por contener elementos indexicales ${ }^{52}$ en su constitución esencial. Esto es, contenidos prácticos.

Otra versión de este mismo fenómeno, desde una tradición filosófica totalmente diferente aunque de especial interés por sus semejanzas con la teoría de la simpatía y del espectador imparcial de Smith, es la que proporciona Thomas Nagel. En el libro Equality and Partiality afirma que nosotros, seres humanos, tenemos la capacidad de mirar el mundo desde distintos puntos de vista, los que, grosso modo, pueden denominarse el punto de vista individual y el impersonal. "La mayor parte de nuestra experiencia del mundo, y de nuestros deseos, pertenecen a nuestros puntos de vista individuales: vemos las cosas, por así decirlo, desde aquí. Pero también somos capaces de pensar en el mundo abstrayéndonos de nuestra particular posición en él, abstrayéndonos de quiénes somos”53. La última perspectiva correspondería al punto de vista impersonal, en el que ponemos entre paréntesis nuestra auto-identificación a pesar de que, al menos en lo que respecta a la teoría ética, no suprimimos nuestra identidad de seres humanos (en las ciencias naturales es distinto). A partir de esta constatación Nagel plantea que el punto de vista moral (que no es la perspectiva impersonal) se articula en un proceso en tres etapas, partiendo desde la perspectiva individual. La materia prima es siempre la óptica personal: todos empezamos siempre desde nuestros deseos, intereses y preocupaciones. No obstante, también somos capaces de reconocer que las otras personas son otros “yoes”, con sus propios deseos, intereses y preocupaciones, y pode-

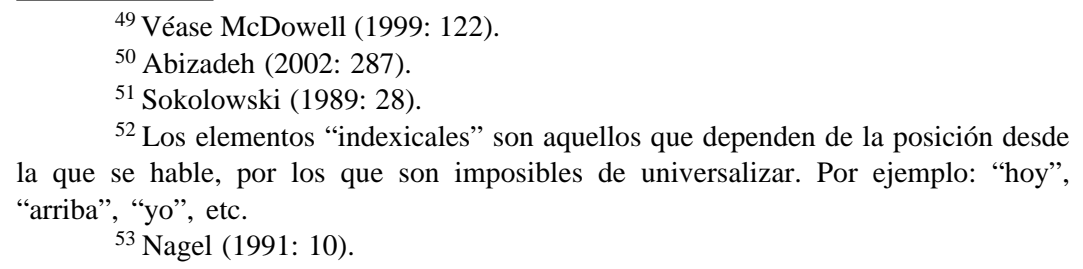


mos salirnos imaginativamente de nuestra particular posición en el mundo y pensar en "todos" sin singularizarnos como un "yo" (como un "yo" distinto de "ellos"). Esta abstracción (o este poner entre paréntesis nuestra propia auto-identificación), que nos lleva a la perspectiva impersonal, corresponde a la segunda etapa del proceso. En ésta, dice el autor, el contenido de nuestros puntos de vista personales no desaparece, sino que sólo dejamos de percibirlo como "mío". Así, desde este punto de vista, somos capaces de darnos cuenta de qué parte del contenido de nuestras perspectivas individuales tiene un valor impersonal real, en el sentido de que es valioso en sí mismo y no sólo valioso para alguien (para mí, por ejemplo. Nagel ilustra este caso con la igualdad y la vida humana $)^{54}$. Por consiguiente, los seres humanos somos capaces ver el mundo simultáneamente desde estos dos puntos de vista, aunque ellos no siempre coinciden y su discordancia puede dividirnos por dentro. ¿Cómo conciliar estas perspectivas? Nagel dice que hay que hacerlo de acuerdo con lo que es razonable o, en sus palabras, de acuerdo "con aquello que puedo afirmar que cualquiera debería hacer si estuviera en mi lugar, y que, por lo tanto, cualquiera convendría conmigo en que, dada esta determinada situación, es lo correcto para mí”55. Esta conciliación vendría a ser el punto de vista moral, una "tercera posición imparcial” 56 que no es ni el punto de vista personal ni el impersonal.

Por otra parte, Nagel también señala que la simpatía es condición de posibilidad para el juicio moral. En este caso distingue entre las que llama perspectiva objetiva y perspectiva interna. Desde la primera, todo nos parece un mero evento (algo así como "el terremoto quebró la porcelana favorita de mi madre”). Desde la segunda perspectiva, en cambio, elogiamos o culpamos al agente que produce ese acontecimiento, ya que lo reconocemos como un ser con intenciones que ha actuado de manera deliberada (por ejemplo, "yo estaba enojada con mi madre y quebré su porcelana"). Pero dado que soy un ser con intenciones, vale decir, sé que mi intención era quebrar esa porcelana y de hecho así lo hice, en una reflexión posterior me reprocho a mí misma por causar dolor a otra persona. En consecuencia, el elogio y el reproche (el juicio moral) tienen una relación intrínseca con la capacidad de tener intenciones. Luego, ¿cómo podríamos elogiar o culpar a otras personas si sólo percibimos su actuación externa, el "mero evento" (como el terremoto)? Nagel afirma que cuando alabamos o reprochamos a un agente no sólo hemos experimentado eventos sino que además le hemos

\footnotetext{
${ }^{54}$ Véase Nagel (1991: 10-14).

${ }^{55}$ Nagel (1991: 17). Esta misma idea se desarrolla en Mortal Questions (1979:
} 128-141).

56 TSM III.3.2, 257. 
atribuido esas acciones. Por medio de la simpatía, que es un acto de la imaginación, somos capaces de entrar en la perspectiva interna de los agentes y percibirlos como seres con intenciones, tal como nos percibimos a nosotros mismos. Así, sólo después de que la simpatía nos ha permitido identificarnos con el agente podemos evaluar moralmente ${ }^{57}$.

En consecuencia, y aunque muy breve y esquemáticamente descritas, estas dos versiones contemporáneas de la operación propia de la razón práctica reconocen la interacción entre dos niveles diferentes (universalidad-particularidad; impersonalidad-personalidad) y la necesidad de que exista algún tipo de síntesis o mediación entre ellos. Ambas también requieren que esa síntesis sea razonable o, en otras palabras, que se use adecuadamente la razón impersonal en la consideración de las infinitas circunstancias de la situación particular, incluyendo al agente específico que interviene. De acuerdo con esto, y tal como afirma Abizadeh: "El corolario es que el ethos y el pathos son, junto con la demostración lógica, elementos constitutivos de la phronesis: los tres en conjunto, pero no individualmente, son la guía necesaria para que la deliberación práctica llegue a sus conclusiones"58. El ethos y el pathos, por ejemplo, con su recuerdo de las experiencias pasadas, complementan al logos abstracto en su difícil tarea de dar forma e inteligibilidad a la realidad contingente. Así pues, como la razón práctica "se ocupa tanto de los particulares como de los universales, y los particulares se conocen a partir de la empeira" 59 , la percepción, las emociones, el carácter, las costumbres y todo aquello incluido en nuestra experiencia es importante para el ejercicio de esta facultad.

Mi tesis, que se hará más clara en la próxima sección, es que en la TSM Adam Smith describe precisamente el funcionamiento de la razón práctica. Desvela la "heterogeneidad categorial” y la función de la facultad de juicio, o algo bastante similar a la prudencia aristotélica, como encarnadas en el espectador imparcial, aunque su manera de abordar este fenómeno sea mucho más fenomenológica que la del filósofo griego. También apunta a la interacción de puntos de vista aludida por Nagel, destacando el papel fun-

${ }^{57}$ En la TSM Adam Smith, describiendo el objeto propio del resentimiento, afirma algo sorprendentemente similar (véase TSM II.iii.1.1, 201). Dice que no basta que este objeto haya sido el causante del dolor, ni tampoco que sea capaz de sentir dolor. El objeto propio del resentimiento (y por tanto del reproche moral) es aquel que ha causado un daño a propósito, que lo ha intencionado. En otras palabras, tiene que ser un ser capaz de tener intenciones, con el que hemos podido simpatizar. Todo acto de simpatía implica esta igualdad básica en cuanto seres capaces de tener intenciones. Con todo, resulta más fácil visualizarlo en estos juicios negativos o de reproche moral.

${ }^{58}$ Abizadeh (2002: 279).

${ }^{59}$ Ibídem: 287. 
damental de la imaginación y la simpatía. Asimismo, en su teoría ética encontramos otros aspectos fundamentales de los sistemas de razón práctica: la imposibilidad de que existan reglas necesarias debido a la marcada e inevitable dependencia del contexto ${ }^{60}$; la existencia de elementos centrales que no se pueden universalizar (Smith los calificará de "indefinibles") ${ }^{61}$; la percepción inmediata ${ }^{62}$; el que no haya relativismo a pesar de que el juicio dependa de las circunstancias y deba reformularse en cada caso ${ }^{63}$; y que el juicio se haga de modo tan rápido que difícilmente somos conscientes de él, pues hemos adquirido el hábito de juzgar así ${ }^{64}$. En resumen, y a pesar de todas las diferencias particulares que pudieran existir, mi propuesta es que la teoría moral de Adam Smith podría interpretarse como una ética de la razón práctica que utiliza la figura del espectador imparcial como metáfora de la facultad de juicio. Lo utiliza, posiblemente y en concordancia con la tradición desde la que escribe, como un procedimiento heurístico para minimizar las presuposiciones o compromisos metafísicos.

\section{TSM: teoría de la razón práctica}

En un ya clásico artículo sobre Smith Norbert Waszek postuló que la teoría ética de Adam Smith mostraba tanto un mínimo como un máximo moral ${ }^{65}$, atribuyendo esta distinción entre niveles de moralidad a la influencia estoica en la filosofía de Smith. Esta interpretación se apoya en importantes pasajes de la TSM y en estos últimos años ha sido también respaldada por connotados estudiosos del pensador escocés ${ }^{66}$. Por ejemplo, en la

${ }^{60}$ Véase TSM VI.ii.1.22, 407. Para la explicación de este punto según Aristóteles, véase Nussbaum (1999: 157-158).

${ }^{61}$ En TSM VI.ii.1.22, 407-408, Smith asevera: "[Hay] diferencias y distinciones que, aunque no son imperceptibles, suelen ser, por su refinamiento y delicadeza, absolutamente indefinibles”. Asimismo, Nussbaum, 161, señala: “En la EN, pasaje V [1137b13-32], e implícitamente en el del Libro II [1109b18-23], Aristóteles alude a una segunda característica de lo práctico, su carácter indeterminado o indefinido (al aoriston)".

${ }^{62}$ Véase TSM VII.iii.2.8, 558. Para la visión de Aristóteles, véase EN 6.8, $1142 \mathrm{a} 28$.

${ }^{63}$ Por ejemplo, en TSM VI.ii.1.22, 407-408 expresa: "No necesitamos reglas casuísticas para dirigir nuestra conducta. Para éstas es a menudo imposible adaptarse a todas las diferencias y gradaciones de circunstancias, carácter y situación”.

${ }^{64}$ Véase TSM III.3.3, 258, donde Smith afirma: "El hábito y la experiencia nos han enseñado a hacerlo con tanta facilidad y soltura que apenas si nos percatamos de que lo hacemos”.

${ }^{65}$ Waszek (1984: 591-606).

${ }^{66}$ Por ejemplo, Charles Griswold, James Otteson, y Vivienne Brown. 
Primera Parte de la TSM, Smith distingue entre la virtud y la mera propiedad, llamando a la primera "excelencia, algo inusualmente grandioso y bello [...] que se alza muy por encima de lo que es vulgar y común”67. Actuar con propiedad, en cambio, aunque es moralmente correcto, no es actuar virtuosamente ni admirable. Más adelante también se refiere a dos criterios distintos de juicio: "El primero es la idea de la propiedad completa, de la perfección [...] El segundo es la idea de la proximidad o distancia de esta completa perfección a la cual comúnmente llegan las acciones de la mayor parte de los hombres"68. El primero sería la virtud perfecta, la prescripción del supuesto espectador imparcial al hombre perfectamente virtuoso, la acción digna de alabanza. El segundo, en cambio, sería el criterio para "la masa de la humanidad", apropiado pero no admirable.

La mayor parte de la TSM, sin embargo, describe el "nivel inferior" de la moralidad, el de las personas corrientes, de la "masa”. Ésta es sin duda una diferencia importante con la ética aristotélica, que se centra en el phronimos y en la virtud perfecta. Es la “democratización” propia de la Modernidad, donde ya existe el valor de la igualdad. Las éticas antiguas eran, en general, aristocráticas. Las éticas modernas, en cambio, alcanzan a toda la población. De ahí que Charles Griswold y Douglas Den Uyl afirmen que ésta es probablemente la mejor descripción de un sistema ético para una sociedad que ha rechazado los antiguos ideales heroicos, como la excelencia, y ahora cree más en algún tipo de meta horizontal como la armonía y la cooperación social ${ }^{69}$. Con todo, es interesante notar que el sistema de Smith, nuevamente, comprende ambos niveles, conciliando rasgos de las éticas antiguas con las modernas. En este ensayo, sin embargo, me centraré particularmente en el nivel de "la masa", puesto que es al que Smith dedica la mayor parte de su obra, haciendo breves alusiones al nivel superior ${ }^{70}$. Intentaré reconstruir este sistema identificando, en primer lugar, cuál es su motivación moral específica; y luego, en segundo término, la justificación moral válida según Smith. De acuerdo con esto, y comparándolos con los

${ }^{67}$ TSM I.i.5.6, 77.

${ }^{68}$ TSM I.i.5.9, 78. Véase también TSM VI.iii.19, 441.

${ }^{69}$ Véase Griswold y Den Uyl (1996: 616). Véase también Griswold (1999: 316).

${ }^{70}$ Un análisis más detallado del nivel superior, correspondiente al hombre de virtud perfecta, puede verse en mi “Adam Smith: Reconstruction of Practical Reason” (2004). La distinción metaética de estos dos niveles, de acuerdo con ese artículo, no es en absoluto trivial, puesto que, allí postulo, la justificación moral del nivel superior (hombres de virtud perfecta) es teleológica, y muy similar a la aristotélica. Mientras que la justificación moral del nivel inferior es más bien deontológica, mucho más parecida a la kantiana. 
elementos propios de las éticas de la razón práctica ya descritos, podremos al fin comprobar en qué medida resulta admisible interpretar la TSM como una ética fundada sobre la razón práctica.

\subsection{Motivación moral y educación moral}

Smith inicia su teoría moral describiendo el fenómeno de la "simpatía”, consciente de la importancia central que tendrá este concepto para la comprensión correcta de su sistema. Para él, la simpatía no consiste en un proceso mecánico, un mero contagio de sentimientos ni en la compasión frente al dolor ajeno. La simpatía, en su primera definición, es "nuestra solidaridad en el sentimiento ante cualquier pasión" "11 que sigue a un intercambio imaginario de situaciones entre el agente y el espectador. Es un impulso natural que nos lleva a identificarnos con el agente/espectador para obtener placer en ese acto. En consecuencia, el mutuo deseo de simpatía (de coincidencia en la emoción) es un deseo natural e innato de placer.

Pero ésta no pareciera ser todavía la motivación moral para Smith. La motivación moral específica es el placer de la coincidencia en la propiedad de la emoción; es decir, el placer de un intercambio simpatético cuando, y sólo cuando, el espectador puede entrar en la motivación del agente porque ella es proporcional a su causa. La peculiaridad del sentimiento moral en Smith es su intencionalidad, esto es, su apertura a contexto, su referencia intrínseca a la situación que se está viviendo. La primera definición que Smith ha dado de la simpatía ("nuestra solidaridad en el sentimiento ante cualquier pasión") habla todavía de un fenómeno psicológico innato, identificado por la psicología contemporánea, que desarrollamos desde muy pequeños $^{72}$. Pero ése es el contagio de sentimientos del que Smith quiere distinguir su definición de simpatía. Ya en la segunda edición de su TSM, y aparentemente replicando a una crítica de su amigo David Hume, hace explícita la distinción entre el placer causado por la identificación psicológica (de un agente y un espectador) de una emoción agradable, y el placer de la coincidencia en la propiedad de la emoción ${ }^{73}$. Éste ya sería el fenómeno moral, la estructura de segundo que se monta sobre esas tendencias de nuestra naturaleza pero no se identifica con ellas.

La distinción fundamental, y que marca una diferencia insalvable entre la — digamos — tendencia a la simpatía innata y a la simpatía moral (o

${ }^{71}$ TSM I.i.1.5, 52. Cabe resaltar que Smith va precisando su concepto de simpatía a lo largo de la obra.

${ }^{72}$ Véase Gordon (1995: 105).

${ }^{73}$ Véase TSM I.iii.1.9, 116- 117. 
de primer y segundo orden), es que en la segunda el objeto de la simpatía no son los sentimientos del otro (un contagio, como el que puede experimentar un perro cuando ve feliz a su amo), sino el objeto de ese sentimien$\mathrm{to}^{74}$. Smith lo deja claro al establecer que la simpatía (moral) se refiere a la coincidencia en la emoción que la situación amerita ${ }^{75}$; o en aquello que la provoca. También al hablar de la simpatía condicional y simpatía ilusoria ${ }^{76}$, donde no existe coincidencia actual en los sentimientos de los involucrados. Tal como lo expresa Michel Malherbe, la simpatía (moral) en Smith es un proceso que entraña una doble relación de conveniencia (o adecuación): la de la pasión del agente con su causa, y la del agente con el espectador ${ }^{77}$. Incluso, siendo aún más precisos, la simpatía en Smith es la adecuación del sentimiento del agente con la causa que lo provoca a través del juicio del espectador.

Así, desde nuestra natural tendencia a la simpatía, que procede de principios innatos de la naturaleza humana ${ }^{78}$, y a través de ciertos procesos de aprendizaje (guiados por el autodominio, ver sección 1), llegamos a experimentar y a desear (a estar motivados para) el placer (moral) de la propiedad. Entonces la "simpatía moral”, siendo natural (no artificial ni impuesta) en el hombre, no es una tendencia innata, sino una estructura de segundo orden que se monta sobre nuestra constitución psicológica, y que incluye en sí algo de deliberación, asimilación y comprensión ${ }^{79}$. Se trata de un sentimiento cognitivo; un sentimiento que también envuelve un sentido de cognición, imaginación, sensibilidad frente a la realidad y permanente adaptación a nuevas circunstancias ${ }^{80}$. Ésta es la simpatía "de segundo orden" que produciría, como afirma Charles Griswold, un "placer de segundo orden”"1.

${ }^{74}$ Véase Darwall (1999: 144).

${ }^{75}$ En TSM I.i.1.10, 54, Smith afirma: "La simpatía, por ende, no deriva tanto de la percepción de la pasión como de la situación que la provoca.”

${ }^{76}$ TSM I.i.3.4, 64 y TMS II.i.2.5, 156, respectivamente.

${ }^{77}$ Véase Malherbe (2000: 418).

${ }^{78}$ Véase Otteson (2002: 84).

${ }^{79}$ Véase Griswold (1999: 88). Cfr. nota 26 más arriba.

${ }^{80}$ Aún podría preguntarse por qué razón tendemos tan fuertemente a la simpatía, sin la cual Smith afirma que ninguna sociedad humana podría existir (véase TSM II.ii.3.1, 185). La respuesta, a mi juicio, se encuentra en una frase recurrente de Smith: "el gran propósito de la vida humana es mejorar nuestra propia condición” (TSM I.iii.2.1, 124. Ésta es también una idea central de Wealth of Nations [La Riqueza de las Naciones]); y naturalmente, Otteson (2002). Por tanto, si esta interpretación es correcta, la motivación moral inmediata en la teoría de Smith procede del placer de la propiedad dentro del intercambio simpatético, y la motivación moral última es, en un sentido amplio, “mejorar nuestra propia condición”.

${ }^{81}$ Griswold (1999: 121). 
Y el deseo de este placer vendría a ser la motivación moral específica en la teoría de Smith; y el que permite que Griswold acertadamente pueda llamarla "la partera de las virtudes" 82 .

En consecuencia, la simpatía, que en su origen es básicamente un sentimiento, aparece, sin embargo, como susceptible de ser inspirada (informada) hasta cierto punto por la razón. Lo anterior queda comprobado claramente con las luces que da Smith acerca de la educación moral. La simpatía, a través del intercambio imaginario, es para Smith —al igual que para Nagel— una condición necesaria del juicio moral. ¿Por qué? Pues para ser capaces de juzgar a otros necesitamos conocer desde un punto de vista interno sus motivos y circunstancias, es decir, necesitamos experiencia. En rigor no es preciso que hayamos vivido exactamente la misma situación; pero sí requerimos contar con un mínimo de experiencia vital para poder reconstruir, al menos parcialmente, la situación del agente. Ése es el motivo por el cual Smith señala que la conducta moral no puede ser enseñada por filósofos, sino por "poetas y escritores de romances [...] [quienes] son, en esos casos, mucho mejores instructores que Zenón, Crisipo y Epícteto"83, ya que el juicio moral no precisa del conocimiento teórico sino el conocimiento experiencial, el que proporciona (además de la vida misma) la literatura, el teatro y, según Aristóteles, hasta la música ${ }^{84}$.

Por consiguiente, la experiencia es imperativa para una educación moral exitosa. Desde que nacemos, de manera natural, comenzamos a buscar el placer —el placer de la simpatía mutua — y a evitar el dolor. Pero pronto nos damos cuenta de que no siempre todos simpatizan con nosotros, e incluso hay veces que algunos reprueban nuestra conducta. Toda esta interacción (primero con nuestra familia, luego con nuestros compañeros de clase, y así sucesivamente) nos ayuda a darnos cuenta de cuáles de nuestros estados de ánimo, nuestras reacciones y palabras, agradan a nuestros semejantes, y cuáles no lo hacen. Gradualmente llegamos así a la conclusión de que debemos "controlar nuestros sentimientos pasivos" nuestras pasiones" 86 , y lograr dominarnos si pretendemos que alguna vez alguien entre en nuestros sentimientos y simpatice con ellos. Esto lo realiza-

${ }^{82}$ Ibídem: 122.

${ }^{83}$ TSM III.3.14, 259.

${ }^{84}$ Véase Poetics 4, 1448b5-23; Rhetoric 1.11, 1371b5-10, y la explicación de Sherman (1999: 240-241). Griswold también ha identificado varias similitudes en este tema (1999: 210). Cabe asimismo resaltar la similitud de este "conocimiento experiencial”, que requiere de la simpatía, con la condición que pone Nagel de considerar al otro como un sujeto con intenciones para realizar el juicio moral.

${ }^{85}$ TSM III.3.21, 273.

${ }^{86}$ TSM III.3.22, 273. 
mos a través de la virtud del autodominio, que será, en definitiva, el verdadero artífice de nuestro carácter, el que corrija nuestras actitudes y nuestra percepción del mundo para hacer que nuestros sentimientos sean los más apropiados para el contexto social ${ }^{87}$.

Obviamente esta virtud, que a través del ejercicio y la habituación "modera”, “corrige” o "controla” nuestros sentimientos, debe ser algo distinto a esos mismos sentimientos. Smith afirma que "a veces reprimimos las pasiones por consideraciones prudenciales respecto de las consecuencias que podrían derivar de su indulgencia”88, específicamente, por la razón instrumental; y en otras ocasiones “aquellas pasiones son reprimidas por el sentido de propiedad, [y por tanto] en algún grado moderadas y sometidas a éste" ${ }^{\text {89 }}$ Sólo esta última "represión" es una manifestación del autodominio: Al percibir que nuestros sentimientos son inadecuados para una situación determinada - lo que significa que nadie simpatizará con nosotros y que no sentiremos ningún placer- la virtud del autodominio nos induce a adaptarlos apropiadamente. Este aprendizaje no tiene por qué ser consciente (como es el aprendizaje teórico), pero evidentemente sí se trata de cierto tipo de ajuste reflexivo de nuestros sentimientos espontáneos en función de alguna idea respecto de qué actitud es la más adecuada para lograr la aprobación de nuestros semejantes. De modo que en la teoría moral de Smith el autodominio incluye claramente algún tipo de deliberación, no es mero sentimiento: es razón práctica.

Por otra parte, Smith también expone una motivación moral perfecta. Señala que: “[El hombre naturalmente] anhela, no sólo la alabanza, sino también ser digno de ella, o ser aquello que, aunque no sea alabado por nadie, constituya, sin embargo, el objeto natural y propio de alabanza"90. Por tanto la motivación moral podría no corresponder sólo al deseo del placer de la simpatía (moral), sino también al deseo de lo alabable, o, como diría Smith, al amor a la virtud ${ }^{91}$. En este punto Griswold comenta que el filósofo escocés “imprime a su ética de la virtud, eminentemente aristotélica,

${ }^{87}$ Compárese con Sherman (1999: 238-239): “Según Aristóteles, la educación correcta consiste en educar a los niños a encontrar el placer y el dolor donde es apropiado (1104b11-13)" y "la educación de nuestras disposiciones para sentir miedo, ira, buena voluntad, compasión o piedad apropiadamente estará estrechamente ligada al hecho de aprender a discernir las circunstancias que justifican estas respuestas”. Compárese con Smith: "El gran secreto de la educación es dirigir la vanidad a los objetos apropiados” (TSM VI.iii.46: 453).

\footnotetext{
${ }^{88}$ TSM VI.concl.3, 465.

${ }^{89}$ TSM VI.concl.4, 466.

${ }^{90}$ TSM III.2.2, 232.

${ }^{91}$ TSM III.2.8, 237.
} 
un interesante giro kantiano"92. El deseo de lo "alabable" —como distinto de lo "alabado" - es el deseo de simpatizar con el propio espectador imparcial, y es el que alejaría a la teoría de Smith del relativismo cultural ${ }^{93}$.

\subsection{Justificación moral: el espectador imparcial}

El espectador imparcial es el gran protagonista de este sistema ético, y no sólo por su novedad sino también porque encarna la subjetivación de la justificación moral. Es un procedimiento heurístico que Smith probablemente utiliza para liberar a su teoría de la necesidad de alguna validación externa en el juicio moral o, lo que es lo mismo, para legitimar la autonomía moral de las personas. Sin embargo, para entender bien esta figura hay que explicar primero la teoría de la imaginación que hay implícita en el texto de Smith, la que no sólo hace posible la simpatía sino además, y como el reverso de este mismo impulso natural, la imparcialidad moral.

Siguiendo a Hume, Smith afirma que la existencia de la sociedad es condición necesaria para la autoconciencia, por cuanto sólo al vernos reflejados en los demás nos percatamos de quiénes y qué somos ${ }^{94}$. Como el punto desde el que se mira queda siempre oculto al observador, sólo podemos conocerlo indirectamente, al verlo reflejado en los demás. Por consiguiente, la autoconciencia (conciencia de mí, de mi punto de observación) sólo aparece con la simpatía: la identificación imaginaria me muestra lo que soy. De este modo la imaginación no es sólo la causa eficiente de la simpatía, sino también, primerísimamente, de la autoconciencia. Con todo, este acto de la imaginación no puede ser una mera reproducción de la percepción de los sentidos, ya que para alcanzar la identificación entre el observador y el observado los particulares no bastan. Si se supone que el observador "entra en" los sentimientos del agente, y reacciona en consecuencia, debe ser capaz de abstraer esos particulares (tal observador y tal observado) en algún tipo de clase a la cual ambos pertenezcan. Por ejemplo, si yo

${ }^{92}$ Griswold (1999: 130).

${ }^{93}$ Esta segunda motivación moral, superior, implicaría también un perfecto dominio de sí mismo y correspondería, en la distinción que hace Waszek (1984, nota 64), al nivel superior de moral, el del hombre perfectamente virtuoso. Sin embargo, con gran realismo Smith reconoce que de algún modo ésta podría ser sólo una distinción analítica, ya que nunca estará suficientemente claro (en los hechos) si una acción proviene o no exclusivamente de ella; y aunque lo estuviera, pareciera ser una necesidad psicológica de todo ser humano el sentirse, en algún momento al menos, aprobado por los demás.

${ }^{94}$ Véase TSM III.1.3, 228-230. 
observo a "Juan llorando por la muerte de su padre" como un suceso externo, desde fuera (o desde el "punto de vista objetivo" de Nagel), no experimento absolutamente ninguna reacción emocional. En cambio si pienso "Juan, un hijo, como yo soy una hija, está llorando por la muerte de su padre” puedo identificarme fácil y espontáneamente con él, y sentir lástima por esa persona. Esta capacidad de universalizar, de reducir los casos particulares a sus categorías esenciales, obviamente implica una cooperación estrecha entre la imaginación y la razón.

El lugar donde mejor se refleja la idea que elabora Smith acerca de este proceso de la imaginación es en su descripción fenomenológica del sentido del deber ${ }^{95}$. Allí dice que cuando nos juzgamos a nosotros mismos nos distanciamos de nuestro propio punto de vista para vernos a la luz bajo la cual nos ven los demás. Imaginamos entonces a una tercera persona: un juez, un "espectador imparcial interior", quien, observando permanentemente nuestra conducta desde esa perspectiva desinteresada - y por lo tanto, en su dimensión verdadera-, es capaz de dictaminar si nuestras acciones son censurables o dignas de alabanza. La imaginación moral, como podría llamarse, mezclaría de este modo la autorreferencia y la no autorreferencia. La primera es mi yo natural, el "yo examinado", donde yo me identifico conmigo misma. La segunda es el "yo juez", que soy realmente yo, pero mirándome a mí misma como desde fuera, como una más dentro de una clase, poniendo entre paréntesis mi autoidentificación ${ }^{96}$. A través de este procedimiento logramos la validación moral de nuestra conducta: renunciamos primero (parcialmente) a nuestra autoidentificación (mirándonos a través de los ojos del espectador), para luego recobrarla ya legitimada. El proceso, con su giro hacia una posición extrínseca (aunque internalizada), corrige las distorsiones del amor a sí mismo y garantiza la corrección moral de nuestra conducta ${ }^{97}$. Este modelo ético, que asigna a la imaginación un papel protagónico en la vida moral, inaugura toda una nueva tradición en la comprensión moderna de la razón práctica.

En consecuencia, cuando simpatizo con otros mediante la identificación imaginaria y renuncio parcialmente a mi autoidentificación para entrar en sus sentimientos, debo retirarme de esa posición céntrica que espontá-

${ }^{95}$ Véase TSM Parte III.

${ }^{96}$ Hay aquí una coincidencia clara con la perspectiva subjetiva y la impersonal de Nagel, que reclaman precisamente una reconciliación.

${ }^{97}$ Aquí es donde cobra mayor relevancia el concepto de igualdad en Smith. Él repite hasta tres veces en su obra que, bajo la luz de la razón, comprendemos que no somos más que uno entre una multitud de iguales, por lo que no parecería moralmente justificable el hacer de nosotros mismos una excepción (véase, por ejemplo, TMS III.3.4, 260). 
neamente ocupo en mi vida y verme a mí misma y a los demás como seres igualmente valiosos. Esta renuncia a la centralidad es, precisamente, la imparcialidad, y es con toda claridad el reverso del mismísimo acto de la simpatía, de la identificación simpatética. El gran mérito de la teoría de Smith, por tanto, fue mostrar cómo la simpatía y la imparcialidad están intrínsecamente unidas, y especialmente iluminar esa segunda perspectiva que comúnmente permanece oculta. Lo hizo, como ya señalé, a través de la figura del espectador imparcial, que se adquiere y desarrolla paulatinamente hasta constituir la personificación de la conciencia moral.

En un comienzo, cuando recién entramos al mundo moral, el espectador imparcial no es más que consenso social internalizado. Sus criterios morales corresponden al promedio de lo que los espectadores reales de mi sociedad suelen elogiar y censurar ${ }^{98}$. Con el tiempo estos criterios podrán ir evolucionando de acuerdo con el desarrollo moral del agente; pero ya desde ese primer momento, el espectador imparcial tiene impresas sus características formales definitivas: después de sucesivos ejercicios imaginativos ${ }^{99}$ consiguió romper con la auto-centralidad natural del agente y alcanzó así la imparcialidad necesaria para ser validado. Él observa desde una perspectiva interna $^{100}$ y delibera, considerando todas las circunstancias disponibles para su conocimiento, y sólo dejando de lado el sesgo de sus emociones privadas $^{101}$. Así se transforma en la fuente de la aprobación moral.

El punto de vista del espectador imparcial —y en este tema, como ya dije al principio, Smith es también un precursor de la ética contemporáneano equivale ni a la neutralidad impersonal (la "luz abstracta y filosófica del estoicismo") ni a la perspectiva centrada en uno mismo ${ }^{102}$. Antes bien, su perspectiva se comprende como esa luz "bajo la cual podemos aparecer naturalmente frente a los demás"103, siendo así una "tercera postura"104, relativa al agente, y que considera mis propios intereses en la medida en

98 Griswold (1999: 183) señala: "El espectador imparcial corresponde a un desarrollo lógico [...] de los rasgos de espectadores reales”.

${ }^{99}$ Véase Brown (1994: 24).

100 Nuevamente, en el sentido de Nagel descrito más arriba. Véase también Griswold (1999: 68), donde compara la perspectiva del espectador imparcial con la objetividad de un crítico de teatro, la cual "se alcanza mediante un distanciamiento relativo, aunque no completo"; y muy especialmente el concepto del punto de vista de la segunda persona en Darwall (1999).

${ }^{101}$ Véase Griswold (1999: 77).

102 Véase, por ejemplo, TSM II.ii.2.1, 180-181, y el clásico ejemplo de TSM III.1.46, 259, donde señala que lo natural es que a uno le importe más que le corten su dedo meñique que un gran cataclismo en China con millones de muertos.

${ }^{103}$ TSM II.ii.2.1, 180-181.

104 TSM III.3.2, 237. 
que posean valor universal ${ }^{105}$ o no estén sesgados por el exceso de amor a mí mismo. De esta manera la posición del espectador imparcial corresponde a una síntesis entre un completo y antinatural desapego a uno mismo (estoico), y el compromiso espontáneo y absoluto con los propios intereses (sentimientos brutos); una conjunción articulada de la interrelación entre estas dos perspectivas distintas ("heterogeneidad categorial”), particularmente parecida al punto de vista moral descrito, por ejemplo, por Wieland y Nagel en la segunda sección de este ensayo.

No obstante, pese a todo lo dicho, el espectador imparcial no es infalible. Puede, por ejemplo, juzgar erradamente cuando nuestros sentimientos no están bien disciplinados y ceden ante los impulsos más poderosos del amor a sí mismo ${ }^{106}$. Pero también puede equivocarse - $-\mathrm{y}$ éste es el punto más interesante puesto que podría permitir a esta ética trascender el relativismo cultural — cuando el criterio que él internalizó, aun cuando cuente con la aprobación de la mayoría de los miembros de esa sociedad, está, en realidad, errado. Smith dedicó largas páginas de la sexta edición de la TSM para clarificar este tema ${ }^{107}$, que representa la posibilidad de elevar nuestras opiniones morales relativistas y emocionales a lo que se podría llamar la "recta razón”. A partir de las pasiones, de estructuras subjetivas e impulsos originarios, Smith puede ahora proponer una ética con cierta pretensión de universalidad. Los pasos para llegar a esta universalidad dependerán, sin embargo, del potencial desarrollo del espectador imparcial. Smith primero afirma que por naturaleza no sólo deseamos la alabanza sino también el ser dignos de ella ${ }^{108}$, es decir, ser el objeto propio de aprobación y, por ende, de autoaprobación. Cuánto nos importe la alabanza externa y cuánto el ser dignos de alabanza dependerá de nuestra sensibilidad moral (desarrollada principalmente por la reflexión y la observación) ${ }^{109}$. El aplauso de los otros "tiene mayor o menor importancia para nosotros, exactamente en la proporción en que estamos más o menos seguros de la propiedad de nuestros sentimientos, de la precisión de nuestros juicios”110. Para el hom-

\footnotetext{
105 Véase Nagel (1991: 12).

106 Naturalmente ésta es una situación en la que el espectador imparcial deja de ser "imparcial", de modo que sería más preciso decir que en estos casos, más que equivocarse, el espectador imparcial simplemente desaparece. Sin embargo, desde un punto de vista psicológico, podemos ser incapaces de advertir su ausencia y autoconvencernos, en cambio, de que esos juicios que oímos en nuestra conciencia son sus juicios imparciales y no aquello que estamos empeñados en escuchar.

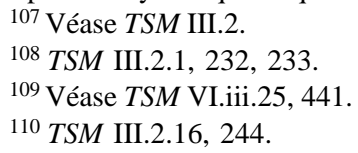


bre sabio, por ejemplo, "su autoaprobación [...] no requiere la confirmación de la aprobación de otros hombres. Por sí sola es suficiente y a él le basta [...] El amor por ella es el amor por la virtud"111. Éste es el punto de fuga, donde el espectador imparcial, que originalmente era la personificación del consenso social, se transforma en un espectador imparcial ideal ${ }^{112}$ o, en otras palabras, en aquel que ha reflexionado sobre qué es bueno y malo en sí mismo ${ }^{113}$ : aquel que representa la verdadera autonomía moral.

\subsection{Imparcialidad}

Si asumimos que Smith efectivamente "se mueve tanto en el nivel superior como en el inferior" 114 de la ética, el mínimo ético que Smith exige como justificación moral para el grueso de la humanidad es la imparcialidad, entendida al modo moderno, vale decir, estrictamente unida a la universalidad $^{115}$. En general, las teorías éticas contemporáneas consideran que la imparcialidad y la universalidad son condiciones necesarias para una justificación racional de la moral. Hay dos "pruebas de imparcialidad" ampliamente conocidas: una es la de Richard M. Hare (un juicio es imparcial si y sólo si se aprueba que cualquier persona, enfrentada a las mismas circunstancias, actúe de la misma manera); y la otra es la de reversibilidad de Kurt Baier (actuamos imparcialmente si y sólo si actuaríamos de la misma manera en caso de que los papeles se intercambiaran) ${ }^{116}$. Adam Smith, con doscientos años de anticipación, introdujo estas mismas ideas como fundamento de su teoría moral. Con la figura del espectador imparcial incorporó la universalidad y la imparcialidad, dos elementos específicamente modernos, como garantía de corrección moral. Y adicionalmente, con la simpatía, trazó el retrato fenomenológico de la reversibilidad, formalizando por primera vez esta intuición milenaria y transformándola en el núcleo de un sistema moral abstracto.

${ }^{111}$ TSM III.2.8, 236-237.

112 Véase Haakonssen (2002: xxii). En su introducción, Haakonssen señala: “Es indudable que Smith llega, especialmente en la última edición, a describir con mayor claridad nuestra tendencia a transformar al espectador imparcial social en un juez idealizado".

113 Véase Miller (1996: 194)

114 Véase Griswold (1999: 225).

${ }^{115}$ En el nivel superior, como ya señalé, se podría tal vez hablar de una justificación teleológica; pero este tema no lo desarrollaré en el presente ensayo. Véase mi “Adam Smith: Modern Reconstruction of Practical Reason” (2004).

116 Véase la voz "imparcialidad" definida por Gert en The Encyclopedia of Ethics (1992: 599-600). 
Con todo, Smith reconoce la debilidad del ser humano y la omnipresente posibilidad del autoengaño ${ }^{117}$. Cuando nuestros principales intereses están en juego, o cuando nuestros sentimientos no están bien disciplinados, la voz del espectador imparcial tiende a apagarse gradualmente. Cuando las pasiones bloquean nuestra conciencia y nuestra imaginación nos engaña, el espectador imparcial queda indefenso. Para estas situaciones $-\mathrm{y}$ dado que quien padece de autoengaño es incapaz de reconocer el error desde dentro- Smith postula la necesidad de reglas morales: un recurso externo, siempre disponible, construido a partir de infinitas experiencias particulares de intercambios simpatéticos en la sociedad y cuya función es evitar el engaño moral generalizado ${ }^{118}$. Teniendo en cuenta esta situación Samuel Fleischacker considera que las reglas morales son la cima del sistema ético de Smith ${ }^{119}$, y en ese sentido, como el último recurso o la garantía en contra de los errores, ciertamente está en lo cierto. Pero aun así Smith conoce y declara la imprecisión de las reglas morales —con excepción de las reglas de justicia- y la superioridad de la facultad del juicio, siempre que no estemos autoengañados. Las reglas, que son normas generales y abstractas, jamás podrán tener en cuenta todas las circunstancias en juego, el marco situacional completo de las acciones particulares ${ }^{120}$. En consecuencia, todo lo que las reglas pueden hacer es marcar un mínimo ético, el punto de propiedad que en general se espera del hombre medio; pero dejan abierto al juicio de cada individuo todo el ámbito propio de la virtud, el de la excelencia.

En consecuencia, la justificación moral (o verdad práctica) en el sistema de Smith parecería ser más bien deontológica. Lo que el espectador imparcial evalúa es la propiedad de la acción, que tiene dos condiciones: que el deseo que la origine sea recto, y que sea proporcional a la situación vivida. Dadas estas dos condiciones, la acción es aceptable desde un punto moral. En principio, el espectador no evalúa que la acción sea coherente con el proyecto general de vida del agente, lo que sería una justificación teleológica, como la aristotélica, y que Smith no exige a los ciudadanos. Pide la propiedad, no la virtud o excelencia. En el ámbito político ocurre algo análogo: se exige la justicia (ése es el test de aceptabilidad moral), pero no la benevolencia ${ }^{121}$.

117 Véase TSM III.4.6, 290-291.

${ }^{118}$ Véase Fleischacker (1991: 256).

119 Ibídem, 261.

${ }^{120}$ Véase la sección 2, más arriba.

${ }^{121}$ Un desarrollo más completo de este tema se encuentra en mi “Adam Smith: Liberalismo y Razón Práctica” (2006). 
Con todo, en esta ética también se podría postular una justificación teleológica para los pocos (si acaso existen) hombres de virtud perfecta. Sin intención de desarrollar este tema, en la sexta parte agregada a la sexta edición de su TSM, Smith afirma que "El hombre sabio y virtuoso dirige su atención principalmente al primer criterio; a la idea de propiedad exacta y perfecta. En la mente de cada hombre existe una idea de este tipo, que se forma gradualmente a partir de sus observaciones sobre los caracteres y conducta de sí mismo y de los demás [...] Esta idea está delineada con mayor o menor precisión dentro de cada hombre [...] de acuerdo con el cuidado y la atención que se emplee al formularla" ${ }^{22}$. Asimismo, "Cada día se mejora algún rasgo; cada día corrige alguna imperfección. Él ha estudiado esta idea más que cualquier otra persona, la comprende con mayor claridad, se ha formado una imagen más correcta, y está mucho más profundamente enamorado de su exquisita y divina belleza. Él hace su mejor esfuerzo por asimilar su propio carácter a este arquetipo de perfección”123.

A pesar de la extensión de esta cita, me parece que vale la pena copiarla entera ya que muestra, con gran claridad, que en la teoría de Smith “el hombre sabio y virtuoso" organiza su vida y decide sus acciones en función de un cierto ideal, de algún “arquetipo de perfección”, que lo atrae como causa final. Y este razonamiento teleológico, la cumbre de la vida moral, es perfectamente compatible con el resto de su sistema. Primero, para llegar a esta etapa, es preciso haber pasado antes por todas las fases previas (deseo de alabanza externa, educación moral de los sentimientos pasivos, etc.). Y luego, que es el punto más importante, el espectador imparcial - o espectador imparcial ideal, en este caso - no desaparece en esta etapa sino que está más activo que nunca, ya que el hombre virtuoso no es nada distinto al agente que se identifica habitualmente con el supuesto espectador imparcial y busca sólo su simpatía y su aprobación ${ }^{124}$.

En resumen, y como lo han señalado diversos estudiosos de Smith, la TSM establece un mínimo moral y apunta también a un máximo, siempre reconociendo que todo hombre busca siempre mejorar su propia condición ${ }^{125}$. Hay también muchos autores que niegan el elemento teleológico en

${ }^{122}$ TSM VI.iii.25, 441-442. Cursivas mías.

123 Ibídem: 442. Cursivas mías.

${ }^{124}$ Véase TSM III.3.28, 273. El arquetipo de perfección que el hombre sabio y virtuoso intentaría emular, es el que Smith asimila explícitamente al "sabio Académico o Peripatético”. Véase TSM VI.i.15, 387. Un mayor desarrollo de esta idea está en mi “Adam Smith: Reconstruction of Practical Reason” (2006).

${ }^{125}$ Para la gran mayoría de la humanidad esto significará la adquisición de bienes y riquezas, pero para el hombre sabio la felicidad estará en la virtud (véase TSM I.iii.3.1 y I.iii.3.2, 139-140). 
la ética de Smith, o afirman que ella no apunta hacia la perfección personal sino sólo a la cooperación social ${ }^{126}$. Estos autores sólo tienen la mitad de la verdad. La otra mitad está en manos de aquellos que, como Vivenza o Berns, indican que el espíritu de la TSM es mucho más aristotélico de lo que parece a primera vista.

\subsection{Teoría de la razón práctica de Adam Smith}

La teoría moral de Adam Smith parte desde los impulsos humanos naturales — distintas manifestaciones del deseo de placer- y se eleva hacia un mundo común con un orden moral objetivo. Sus dos características principales, y los operadores que permiten la construcción de esta ética marcadamente empirista, son la simpatía y el espectador imparcial. La primera, que es innata pero susceptible de ser educada a través e la experiencia, explica la percepción y la motivación morales ${ }^{127}$. La segunda, creada y perfeccionada gradualmente, hace las veces de la conciencia moral y de la facultad de juicio; prescribe y aprueba ${ }^{128}$, y contiene en sí la potencialidad de trascender el relativismo cultural, es decir, alcanzar alguna universalidad moral.

La TSM de Smith no es un catálogo rígido de normas sino la identificación de ciertos principios prácticos del ser humano ${ }^{129}$; es la descripción de cómo interactuamos y guiamos nuestras vidas. Smith excluye las explicaciones metafísicas, reemplazando algunas por aquellos "deseos humanos originarios impresos en nosotros por la Naturaleza”. Sin embargo, estos impulsos innatos son sólo la materia prima de la moralidad, pues tienen que ser modulados y disciplinados por medio del autodominio, montando sobre ellos una estructura de segundo orden que no es arbitraria pero sí adquirida; no es innata pero sí natural. El autodominio seguirá a cierta autoevaluación reflexiva ${ }^{130}$, aunque no a una reflexión teórica. La comprensión moral es práctica, pero es comprensión. Nuestra idea de felicidad, que es la que otorga un sentido de integración reflexiva — de integridad- a nuestras vidas, suele ser difícil de expresar en palabras, pero es una idea real — cognitiva, formada gradualmente y capaz de orientar nuestras vidas y de proporcionar la justificación última de nuestras acciones. Esta idea va a

${ }^{126}$ Véase Griswold y Den Uyl (1996: 616). Véase también Griswold (1999: 316).

${ }^{127}$ Véase Griswold (1998: 192).

128 Véase VI.iii.19: 438.

${ }^{129}$ Véase Haakonssen (1998: 206).

${ }^{130}$ Véase Griswold (1999: 105). 
estar siempre iluminando nuestro horizonte, al margen de la justificación particular o inmediata que encontremos para alguna de nuestras acciones concretas. Y es la idea, finalmente, que inspira nuestra virtud del autodominio, entendiéndola — según me parece que es la mejor interpretación para la teoría de Smith - no como el simple autocontrol sino más bien como la auto-dirección de la propia vida ${ }^{131}$.

En el sistema de razón práctica de Smith (al igual que en el de Aristóteles) el límite entre los sentimientos y la reflexión no está claramente trazado ${ }^{132}$, y éste puede ser el motivo por el cual se le ha malinterpretado con tanta frecuencia. Para Smith, el juicio ya está montado sobre la emoción ${ }^{133}$, y esto es precisamente lo que permite que su teoría sea sensible al contexto (reencontrando el punto de propiedad en cada ocasión) ${ }^{134}$, y capaz de comprender toda la complejidad de la percepción moral y de construir un sistema absolutamente relativo al agente y, por ello, razonablemente plausible. Asimismo, cuando señala que "las diferencias morales son indefinibles, mas no imperceptibles”135, apunta exactamente a la misma idea. En la sección segunda, más arriba, me referí a la "heterogeneidad categorial" con la que la razón práctica se ve obligada a tratar ante la imposibilidad de reducir todo a la universalidad (o de "definir" todo), y la necesidad de otra instancia que pueda salvar la brecha entre la particularidad y la universalidad. En la teoría de Smith esa función la cumple el espectador imparcial, quien nos dice en cada ocasión cómo hemos de sentir y cómo juzgar. Y en los hombres de virtud perfecta, los que han superado la dependencia de la aprobación social, es este espectador imparcial ideal —y no la razón universal ni los sentimientos sin educar - el que es la norma, la medida, de la virtud ${ }^{136}$. De este modo se conquista la autonomía moral.

${ }^{131}$ Véase Montes, "Smith on virtues: Vir virtutis discourse and civic humanism”, en su Adam Smith in Context (2003: 94). En este capítulo plantea que el concepto de self-command tendría su raíz en la virtud socrática de la enkrateia, literalmente auto-dirección. Esta, a su vez, tiene un interesante vínculo con la ética aristotélica, en particular con la virtud cardinal sophrosyne, lo cual le permite al autor interpretar esta virtud no solamente como una virtud negativa de auto-control, sino también como una virtud positiva.

132 Véase Griswold (1999: 138), y Nussbaum (1999: 170). Nussbaum afirma que: “Aristóteles no realiza una clara división entre lo cognitivo y lo emotivo".

${ }^{133}$ Véase Griswold (1999: 192).

${ }^{134}$ Véase TSM VI.iii.14, 434. Paralelamente, de acuerdo con Nussbaum, la percepción moral en Aristóteles es "un tipo complejo de sensibilidad frente a las características dominantes de cada situación concreta” (1999: 146).

${ }^{135}$ Véase TSM VI.ii.1.22, 407-408.

${ }^{136}$ Véase TSM VII.ii.3.21, 533. Ésta es exactamente la misma idea del phronimos aristotélico, por ejemplo, en EN 1113a32-33. 
En suma, en la TSM la "heterogeneidad categorial” propia de la razón práctica se oculta en la imaginación a través de la figura del espectador imparcial. Se asumen las contingencias, seleccionadas de acuerdo con su importancia para cada caso en particular, y se ordenan por medio de un principio universal (que es el que permite que exista la imparcialidad en vez de la autoidentificación absoluta). Por tanto, existe un cierto grado de distanciamiento pero no una completa neutralidad, como la de la razón teórica o la del "punto de vista filosófico". En el pensamiento de Smith, la imparcialidad o la objetividad moral no es meta-empírica ni meta-sensible, sino que, por el contrario, surge a partir de las mismas exigencias de las pasiones ${ }^{137}$. En la TSM los sentimientos son la base, la materia moral específica. Pero tienen que ser corregidos y habituados por el autodominio que, guiado por la razón, actúa moderándolos y moldeándolos apropiadamente, vale decir, de manera razonable. Sólo entonces, al completarse todas las etapas del proceso, esos sentimientos pueden ser propiamente llamados "sentimientos morales".

\section{Conclusión}

En este ensayo he intentado mostrar que la teoría moral de Adam Smith se apoya en la operación propia de la razón práctica. Desde que se publicó por primera vez el libro, en el siglo XVIII, se han propuesto innumerables interpretaciones para esta ética. La más popular es la que dice que ella depende de los sentimientos — con toda su gama de calificaciones adicionales-, aunque hay también otras que van desde el consecuencialismo hasta la deontología. Si mi lectura del texto es correcta, esta infinidad de interpretaciones se explicaría porque la razón práctica constituye, en sí misma, un principio antirreduccionista que abarca los sentimientos, la razón, los hábitos, la preocupación por las consecuencias y la existencia de reglas. Además, en la TSM en particular, como gráficamente expresa Gloria Vivenza, Adam Smith "toma elementos diversos de variadas partes de las filosofías antiguas, incluyéndolos todos, según el grado en el que coinciden con sus propias ideas, [en] lo que podría llamarse un enfoque ‘alquímico’ [de la filosofía] [...]”138. Según esta autora, entonces, Smith sacó elementos de las más diversas tradiciones, incluidos los clásicos y sus contemporáneos Hume y Hutcheson, y los armonizó en un sistema coherente. "Más que una serie de autoridades a las que se debía homenajear, las fuentes antiguas

137 Véase Tasset (1989: 205).

138 Vivenza (2001: 81). 
fueron [para Smith] como un humus de semillas culturales desde el que una nueva especie de ética podía crecer y echar raíces”"139.

En este sentido, y pese a que aquí me he empeñado en destacar las influencias aristotélicas de su teoría, Smith no es simplemente un aristotélico. Sin duda existen muchos elementos que efectivamente coinciden entre ambos $^{140}$, aunque, en mi opinión, la concordancia más importante reside la intuición fundamental que subyace a estos dos sistemas morales: la moderación y el realismo en un sistema articulado por lo que Aristóteles llamó razón práctica ${ }^{141}$. Lo anterior incluye el hecho de considerar la experiencia y el sentido común como el punto de partida y el criterio permanente de validación de dichos sistemas; la integración de los aspectos positivos de otras teorías en un sistema coherente; la importancia capital del conocimiento pre-teórico y del punto de vista interno, junto con la naturaleza social de los seres humanos y el dualismo y posible integración de la razón y los sentimientos. Obviamente sus estilos difieren, pero en alguna medida se complementan entre sí. Como señala Lawrence Berns, "Smith ofrece una versión psicológica increíblemente plausible de las cosas, particularmente del lado sentimental de la ética, el que Aristóteles observó, apuntó y mencionó, pero no explicó en detalle"142.

Con todo, Adam Smith es un pensador ilustrado, que sin saberlo unifica esta versión clásica de la razón práctica con la importante versión moderna que Kant ofrecería algunos años después ${ }^{143}$. Con los mismos elementos que utiliza para fundamentar el nivel superior de la virtud y la excelencia, introduce y da fundamento racional a una ética de deberes morales y normas mínimas. Smith funda los deberes en las virtudes, concilia la exce-

139 Ibídem: 41.

${ }^{140}$ El propio Smith señala algunas de estas coincidencias. Por ejemplo, al exponer la naturaleza de la virtud en los distintos sistemas morales, elogia "la opinión [de Aristóteles] de que ninguna convicción del entendimiento es capaz de superar los hábitos inveterados, y de que la bondad moral no surge del conocimiento sino de la acción” (TSM VII.ii.1.14, 486), en contraste con el intelectualismo de Platón y de los estoicos. Smith también indica que su idea de la virtud se corresponde en gran medida a la de Aristóteles (TSM VII.ii.1.12, 484), para quien ésta "consiste en el hábito del término medio de acuerdo con la recta razón” (TSM VII.ii.1.12, 484). Otra similitud importante es que el juicio moral es sólo posible en los casos particulares.

${ }^{141}$ En cuanto a la influencia de los estoicos, que junto con la de Hume es la más explícita y obvia, Vivienne Brown (1994: 5) afirma que existe "una dependencia simultánea, aunque en último término un rechazo, a la filosofía estoica en la TSM”. Griswold y Vivenza comparten este diagnóstico.

142 Berns (1994: 74-75).

${ }^{143}$ Me refiero fundamentalmente a la universalidad y a la imparcialidad de los juicios morales, y a esa peculiar deontología con que se podrían justificar. 
lencia con la debilidad y la imperfección humanas, y propone, en los albores de la Modernidad, un sistema que une la teleología y la deontología, las dos filosofías morales parciales que han estado en disputa durante los últimos doscientos años.

\section{REFERENCIAS BIBLIOGRÁFICAS}

a) Abreviación y referencias de La Teoría de los Sentimientos Morales.

TSM

La Teoría de los Sentimientos Morales

[TMS, The Theory of Moral Sentiments].

Las referencias siguen las divisiones y párrafo(s) de la edición en inglés de Liberty Fund (Liberty Classics, 1976), que es una reproducción fotográfica de la publicada por Oxford University Press $(1976,1979)$, basada a su vez en la edición de la Universidad de Glasgow. Las páginas corresponden a la edición en castellano de Carlos Rodríguez Braun (Alianza, 1997).

\section{b) Otros autores citados}

Abizadeh, Arash: "The Passions of the Wise: Phronesis, Rhetoric and Aristotle's Passionate Practical Deliberation”. En The Review of Metaphysics, 56 (2002).

Aristóteles: Nichomaquean Ethics (EN) [Ética a Nicómaco]. En Jonathan Barnes (ed.), The Complete Works of Aristotle. Princeton: Princeton University Press, 1984.

Rethoric. En Jonathan Barnes (ed.), The Complete Works of Aristotle. Princeton: Princeton University Press, 1984.

- Poetics. En Jonathan Barnes (ed.), The Complete Works of Aristotle. Princeton: Princeton University Press, 1984.

Baillie, Harold: “Learning the Emotions”. En The New Scholasticism, 62 (1988).

Barnes, Jonathan (ed.): The Complete Works of Aristotle. Princeton: Princeton University Press, 1984.

Berns, Lawrence: “Aristotle and Adam Smith on Justice: Cooperation between Ancients and Moderns?”. En Review of Metaphysics, 48 (1994).

Brown, Vivienne: Adam Smith's Discourse. Canonicity, Commerce and Conscience. Nueva York: Routledge, 1994.

Burnyeat, Myles F.: “Aristotle on Learning to Be Good”. En Amélie Oksenberg Rorty (ed.), Essays on Aristotle's Ethics. Berkeley: University of California Press, 1980.

Carrasco, M. Alejandra: “Adam Smith: Reconstruction of Practical Reason”. En The Review of Metaphysics, 58 (2004).

“Adam Smith: Liberalismo y Razón Práctica”. En Pensamiento. Revista de Investigación e Información Filosófica, Vol. 62, № 232 (2006).

Cooper, John: Reason and Human Good in Aristotle. Cambridge: Harvard University Press, 1975. 
Darwall, Stephen: "Sympathetic Liberalism: Recent Work on Adam Smith”. En Philosophy and Public Affairs, 28 (1999).

Fleischacker, Samuel: "Philosophy in Moral Practice: Kant and Adam Smith”. En Kant Studien, 82 (1991).

A Third Concept of Liberty: Judgment and Freedom in Kant and Adam Smith. Princeton: Princeton University Press, 1999.

On Adam Smith's Wealth of Nations: A Philosophical Companion. Princeton: Princeton University Press, 2004.

Gert, Bernard: "Imparcialidad”. En Laurence Becker y Charlotte Becker (eds.), The Encyclopedia of Ethics. Garland: 1992.

Gordon, Robert: "Sympathy, Simulation and the Impartial Spectator". En Ethics, 105 (1995).

Griswold, Charles: "Nature and Philosophy: Adam Smith on Stoicism, Aesthetic Reconciliation and Imagination”. En Knud Haakonssen (ed.), Adam Smith. Brookfield: Ashgate, Darthmouth, 1998.

- Adam Smith and the Virtues of Enlightenment. Nueva York: Cambridge University Press, 1999.

Griswold, Charles, y Douglas Den Uyl: “Adam Smith on Friendship and Love”. En The Review of Metaphysics, 49 (1996).

Haakonssen, Knud: “What Might Properly Be Called Natural Jurisprudence?”. En Knud Haakonssen (ed.), Adam Smith. Brookfield: Ashgate, Darthmouth, 1998.

(ed.): Adam Smith, The Theory of Moral Sentiments. Cambridge: Cambridge University Press, 2002.

Hutchinson, Douglas S.: The Virtues in Aristotle. Londres: Routledge \& Kegan Paul, 1986.

Irwin, Terence H.: “The Metaphysical and Psychological Basis of Aristotle’s Ethics”. En Amélie Oksenberg Rorty (ed.), Essays on Aristotle’s Ethics. Berkeley: University of California Press, 1980.

Malherbe, Michel: “Adam Smith et l'Idée d'une Science Morale”. En Revue de Philosophie de la France et l'Étranger, 4 (2000).

McDowell, John: “Virtue and Reason”. En Nancy Sherman (ed.), Aristotle's Ethics. Critical Essays. Lanham: Rowman and Littlefield, 1999.

Miller, Eric: "Sympathetic Exchange: Adam Smith and Punishment”. En Ratio Juris 9, $\mathrm{N}^{\circ} 2$ (1996).

Montes, Leonidas: Adam Smith in Context. Cambridge: Cambridge University Press, 2003.

Nagel, Thomas: Mortal Questions. Nueva York: Cambridge University Press, 1979. Equality and Partiality. Nueva York: Oxford University Press, 1991.

Nussbaum, Martha C.: "The Discernment of Perception: An Aristotelian Conception on Private and Public Rationality”. En Nancy Sherman (ed.), Aristotle's Ethics. Critical Essays. Lanham: Rowman \& Littlefield, 1999.

Otteson, James: Adam Smith's Marketplace of Life. Cambridge University Press, 2002.

Sherman, Nancy: “The Habituation of Character”. En Nancy Sherman (ed.), Aristotle's Ethics. Critical Essays. Lanham: Rowman \& Littlefield, 1999.

Sokolowski, Robert: “What is Moral Action?”. En New Scholasticism, 63 (1989).

Tasset, José Luis: “La Ética de Adam Smith: Hacia un Utilitarismo de la Simpatía”. En Themata, 6 (1989). 
Urmson, James Opie: “Aristotle’s Doctrine of the Mean”. En American Philosophical Quarterly, 10 (1973).

Vigo, Alejandro: Zeit und Praxis bei Aristoteles. Freiburg, München: Karl Alber Verlag, 1996.

Vivenza, Gloria: Adam Smith and the Classics Nueva York: Oxford University Press, 2001.

Waszek, Norbert: “Two Concepts of Morality: A Distinction of Adam Smith’s Ethics and its Stoic Origin”. En Journal of the History of Ideas, 45 (1984).

Wieland, Wolfgang: "Praxis und Urteilskraft". En Zeitschrift für Philosophische Forschung 28 (1974). [La traducción de éste y otros textos de Wieland se encuentran en Alejandro Vigo, La Razón y su Praxis: Cuatro Ensayos Filosóficos. Biblos, 1996.]

“Aporien der praktischen Vernunft". En Wissenschaft und Gegenwart, Geisteswissenschaftliche Reihe. Frankfurt: Vittorio Klostermann, 1989. 